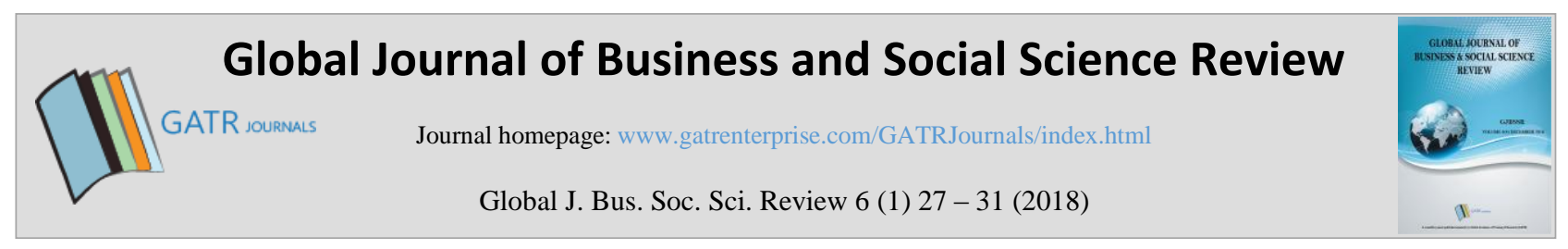

\title{
A Comparative Study of Subjective Well-Being Among Working Mothers in Indonesia and China
}

\author{
Resnia Novitasari $^{1 *}$, Hazhira Qudsyi ${ }^{2}$, Tika Pratiwi Ambarito ${ }^{3}$, Eri Yudhani ${ }^{4}$, \\ Fakhrunnisak $^{5}$, Chenxi Wang ${ }^{6}$, Mingming Liu ${ }^{7}$, Baihua Chen ${ }^{8}$ \\ 1, 2, 3, 4, 5 Department of Psychology, Universitas Islam Indonesia, JalanKaliurang Km. 14 BesiSleman, 55584, Special Province of \\ Yogyakarta, Indonesia \\ ${ }^{6,7,8}$ Department of Psychology and Behavioral Sciences, Zhejiang University, Tianmusan Road No 148, Hangzhou City, Zhejiang
} Province 310000, P.R. China

\begin{abstract}
Objective - This study investigates cross-cultural differences in subjective well-being among working mothers in Indonesia and China, as members of the big five countries with high density populations in the world.

Methodology/Technique - The participants in this study include 168 working mothers, of which 118 are Indonesian and 50 are Chinese. The subjective well-being variable was measured using the Satisfaction with Life Scale (SWLS) and The Scale of Positive and Negative Experiences (SPANE). This study also uses an independent sample t-test to examine the difference between the two.

Findings - The results show that $\mathrm{t}(116)=2.779, \mathrm{p}=0.006$, which indicates that there are different conditions between working mothers in Indonesia and China that affect subjective well-being.

Type of Paper: Empirical.
\end{abstract}

Keywords: China; Indonesia; Comparative Study; Subjective Well-Being; Working Mothers.

JEL Classification: J16, P52.

\section{Introduction}

Subjective well-being has become a prominent topic of research for the employment sphere, particularly for working mothers. Subjective well-being has three main indicators: subjectivity or personal references, positive and negative effects, and comprehensive evaluations of an individual's life (Diener, 1984). Hence, subjective well-being is the result of a personal evaluation, and is closely related with happiness. However, some studies have found that working mothers from various countries face their own unique obstacles

\footnotetext{
* Paper Info: Revised: December 26, 2017

Accepted: February 1, 2018

* Corresponding Author:

Email: resnia.novitasari@uii.ac.id

Affiliation: Department of Psychology, Universitas Islam Indonesia
} 
When trying to balance work and family, which can often lead to increased stress at work (Kumar and Yadav, 2014; Lian and Tam, 2014; Mahpul and Abdullah, 2011). This has raised some issues with respect to mothers' subjective well-being in daily life. Stressors stemming from both work and family present a challenge to working mothers when trying to achieve subjective well-being. The impact of low levels of subjective well-being have been discussed in several studies. Typically, working mothers with high levels of stress tend to have lower levels of subjective well-being (Moreno-Jimenez et al., 2008; Koyuncu, Burke, and Wolpin, 2012; Marshall and Tracy, 2009) and a negative satisfaction with life (Moreno-Jimenez et al., 2008). One of the primary sources of stress working mothers is their role as both mother and employee, which can also contribute significantly to mental health issues among this group.

The issue of subjective well-being among working mothers needs to be further explored in a cross-cultural context. This study aims to develop an understanding of this issue in two countries, namely Indonesia and China, which have several similarities and differences worth examining. Both countries are part of the Asian culture, which is closely related with collectivism (Hofstede, 2011). From a development strategy view, both countries' economies have shown tremendous growth accompanied by a decrease in poverty rates. However, Indonesia has proven faster than China when it comes to adapting to those changes (Hofman, Zhao, and Ishihara, 2007).

An examination of subjective well-being in working mothers between Indonesia and China has not been widely researched to date. From a cultural perspective, Diener (2000) states that subjective well-being is assessed in some nations by using college students as research subjects. Indonesia and China were also included in this research. The results found that there are different values of life satisfaction and happiness in the frequency of which the students thought of, and how important they considered, the value of those variables. Indonesia received a higher score than China in all aspects of this study. From this research, it was assumed that the subjective well-being of Indonesian working mothers was therefore different to that of Chinese working mothers.

Based on the above, this study will analyze the subjective well-being of working mothers among Indonesia and China. Therefore, the proposed research question is: "are there any differences in subjective well-being among working mothers in Indonesia and China?"

\section{Research Methodology}

\subsection{The Characteristics of the Subjects}

This study examines 168 subjects from both Indonesia and China. The selection criteria for the subjects include women who are working and having children. The subjects include 118 working mothers from Indonesia, with the majority being from Yogyakarta, and 50 working mothers from Hang Zhou, China. The age range for 166 subjects ( 2 subjects did not reveal their age) was $22-63$ years old $(M=43.22, S D=9.111)$. For the Indonesian subjects, the age range was $24-60$ years old $(M=43.34, \mathrm{SD}=9.647)$ and for the Chinese subjects it was $22-63$ years old $(\mathrm{M}=42.94, \mathrm{SD}=7.810)$. The description of subjects' work is displayed below:

Table 1. Descriptive Data of Work in China

\begin{tabular}{lcc}
\hline Type of Work & n & Percentage \\
\hline Public sectors & 7 & $14 \%$ \\
Private sectors & 3 & $6 \%$ \\
Entrepreneurship & 25 & $50 \%$ \\
Others & 15 & $30 \%$ \\
\hline
\end{tabular}




\begin{tabular}{lcc}
\hline Total & 50 & $100 \%$ \\
\hline
\end{tabular}

Table 2. Descriptive Data of Work in Indonesia

\begin{tabular}{lcc}
\hline Type of Works & n & Percentage \\
\hline Public sectors & 67 & $58.6 \%$ \\
Private sectors & 27 & $22.9 \%$ \\
Entrepreneurship & 2 & $1.7 \%$ \\
Others & 22 & $18.6 \%$ \\
\hline Total & 118 & $100 \%$ \\
\hline
\end{tabular}

Based on these two tables, some variance in the types of work conducted by the subjects can be seen. There are also some differences between both countries. For example, most Indonesian working mothers are public employees whereas most of the Chinese working mothers are entrepreneurs.

\subsection{Measurements}

This research uses various scales to test the results. The testing of the scales involved 308 participants, both male and female, from China and Indonesia. The scales originate from the English language. Hence, the scales were translated into both Indonesian and Chinese. The scales for assessing subjective well-being were: Satisfaction with Life Scale (SWLS) (Diener, Emmons, Larsen, and Griffin, 1985) and the Scale of Positive and Negative Experience (SPANE), developed by Diener, Wirtz, Tov, Kim-Prieto, Choi, Oishi, and BiswasDiener (2009). Cronbach's alpha coefficient for each Indonesian scale was 0.707 (life satisfaction), 0.714 (SPANE-N), and 0.674 (SPANE-P). In addition, Cronbach's alpha coefficient for each Chinese scale was 0.740 (life satisfaction), 0.921 (SPANE-N), and 0.912 (SPANE-P).

\subsection{Data Analysis Method}

The difference between two variables was assessed using independent sample t-tests to examine the differences of subjective well-being in working mothers.

\section{Results}

The first analysis uses descriptive statistics to describe the ranks of scores on subjective well-being in working mothers.

Table 3. Descriptive Data of Subjective Well-Being in Indonesia and China

\begin{tabular}{lccc}
\hline Countries & Mean & SD & $n$ \\
\hline China & 34.88 & 4.49 & 50 \\
Indonesia & 37.68 & 4.76 & 118 \\
Both Countries & 36.42 & 4.77 & 168 \\
\hline
\end{tabular}

In addition, the study also analyzes the mean differences using an independent sample t-test. The results of the subjective well-being is $\mathrm{t}(116)=2.779, \mathrm{p}=0.006$. This means that the subjective well-being for Indonesian working mothers is significantly higher than Chinese working mothers. Therefore, there is a significant difference in subjective well-being in working mothers. 
The study also examines the differences using the intercept from the origin of countries and types of work as factors ( 2 x 4 ANOVA). The results indicated that those intercepts have no effect on the subjective wellbring of working mothers, as the $\mathrm{F}$ score $(3,160)=0.315, \mathrm{p}=0.815$.

\section{Discussion}

The discussion considers the possibilities of cultural influences on the results. Indonesia has a higher score in subjective well-being in working mothers, when compared to Chinese working mothers. The cultural value of both countries is collectivism, which means individuals are closely connected to the community. Collectivism is a value related to the integration of society. In collectivism, people are bonded with family, groups, and cultures (Hofstede, 2011). Thus, the ties with the social environment are crucial. Individual identity is sometimes blurred with social identity. Conformity is also an important attitude in collectivism. In addition, obedience, which is based on inter-generational positions, supports social interaction.

Nevertheless, there is a difference in specific values. Based on Hofstede (2011), Chinese people have a unique value known as Confucian work dynamism, which is often referred to as long-term orientation. This dimension includes values such as persistence, having a sense of shame, loyalty, and commitment. On the other hand, short-term orientation is characterized by the eagerness to share one's own to avoid social pressure. Indonesia is a country with short-term orientation; it is centered around personal steadiness and stability, attributing success to luck or an external locus of control and service to other people.

A further different value is uncertainty avoidance (Hofstede, 2011). Levels of this value are low in Indonesia while China maintains an average level of uncertainty avoidance. A low level of this value indicates that Indonesia has a high tolerance for chaos and unpredictable conditions, lower stress and a high level of well-being and comfort with ambiguity. In contrast, China has average levels of stress, a need for clarity and structure, and only a mild tolerance for deviant persons or ideas. This is also supported by the conditions of each nation, which is very different. Indonesia for example has hundreds of tribes, local languages, and different faiths and religions whereas China has more commonalities such as race and values. These ideas are emphasized by cultural values of Schwartz (2006) who states that the value of mastery is robust among Chinese people (Schwartz, 2006). Mastery is related to competency, achievement, and competitiveness. However, in Indonesia, their main values emphasize social rules or guidance (Schwartz, 2006).

Many people make decisions based on others' suggestions (Shimazu et al., 2011). Although Shimazu et al. (2011) examines the Japanese population, there is a common value (long-term orientation) shared between Japanese and Chinese societies (Hofstede, 2011). In this study, there is a tendency for East Asian people to become workaholics due to their high activation levels and motivation in work. This also creates stress and other negative effects (Shimazu et al., 2011). Another study by Appleton and Song (2008) found that there are some determinants of subjective well-being among Chinese people in urban areas. Being Communist Party members and participating in politics for instance were found to increase subjective well-being. Indonesia, however, has various political parties and democratic perspectives. Therefore, it is assumed that the political atmosphere has an influence on the subjective well-being of Indonesian people.

\section{Conclusion}

In conclusion, this research has identified a correlation between subjective well-being and work engagement. Furthermore, it also identifies differences between Indonesian and Chinese working mothers which implies that culture plays a significant role in subjective well-being, particularly among working values. However, this study is not without its limitations. Future studies may consider balancing the proportion of subjects between the two subject countries. 


\section{References}

Appleton, S., \& Song, L. (2008). Life satisfaction in urban China: Components and determinants. World Development, 36(11), 2325-2340.

Diener, E. (1984). Subjective well-being.Psychological Bulletin, 95, 542-575

Diener, E. (2000). Subjective well-being: The science of happiness and a proposal for a national index. American psychologist, 55(1), 34.

Diener, E. D., Emmons, R. A., Larsen, R. J., \& Griffin, S. (1985). The satisfaction with life scale. Journal of personality assessment, 49(1), 71-75.

Diener, E., Wirtz, D., Tov, W., Kim-Prieto, C., Choi, D., Oishi, S., \&Biswas-Diener, R. (2009). New measures of wellbeing: Flourishing and positive and negative feelings. Social Indicators Research, 39, 247-266.

Harter, J. K., Schmidt, F. L., \& Keyes, C. L. (2003). Well-being in the workplace and its relationship to business outcomes: A review of the Gallup studies. Flourishing: Positive psychology and the life well-lived, 2, 205-224.

Hofman, B., Zhao*, M., \& Ishihara*, Y. (2007). Asian development strategies: China and Indonesia compared. Bulletin of Indonesian Economic Studies, 43(2), 171-200.

Hofstede, G. (2011). Dimensionalizing cultures: The Hofstede model in context. Online readings in psychology and culture, 2(1), 8.

Koyuncu, M., Burke, R. J., \& Wolpin, J. (2012). Work-family conflict, satisfactions and psychological well-being among women managers and professionals in Turkey. Gender in Management: An International Journal, 27(3), 202-213.

Kular, S., Gatenby, M., Rees, C., Soane, E., \& Truss, K. (2008). Employee engagement: A literature review.

Kumar, A., \&Yadav, M. (2014). Occupational stress among working women: An empirical analysis. Journal of Management Research, 3(1), 199-216.

Lian, S. Y., \& Tam, C. L. (2014). Work stress, coping strategies and resilience: A study among working females. Asian Social Science, 10(12), 41.

Lu, L., Kao, S. F., Siu, O. L., \& Lu, C. Q. (2011). Work stress, Chinese work values, and work well-being in the greater China. The Journal of social psychology, 151(6), 767-783.

Mahpul, I. N., \& Abdullah, N. A. (2011). The prevalence of work-family conflict among mothers in peninsular Malaysia. International Journal of Humanities and Social Sciences, 1(17), 154-161.

Marshall, N. L., \& Tracy, A. J. (2009). After the Baby: Work-Family Conflict and Working Mothers' Psychological Health. Family Relations, 58(4), 380-391.

Moreno-Jiménez, B., Mayo, M., Sanz-Vergel, A. I., Geurts, S., Rodríguez-Muñoz, A., \& Garrosa, E. (2009). Effects of work-family conflict on employees' well-being: The moderating role of recovery strategies. Journal of Occupational Health Psychology, 14(4), 427.

Reggie, T.C. 2012. Work-family conflict and work engagement among working mothers: Personality as a moderator. Minor Dissertation. Magister Commerch, Industrial Psychology, Faculty of Management, University of Johannesburg

Schwartz, S. H. (2006). A theory of cultural value orientations: Explication and applications. Comparative sociology, 5(2), 137-182.

Shimazu, A., Demerouti, E., Bakker, A. B., Shimada, K., \& Kawakami, N. (2011). Workaholism and well-being among Japanese dual-earner couples: A spillover-crossover perspective. Social Science \& Medicine, 73(3), 399-409. 